OPEN ACCESS

Edited by:

Ranjit Kumar Sahoo, All India Institute of Medical Sciences,

Reviewed by:

Prashant Mehta,

Asian Institute of Medical Sciences,

India

Smita Kayal,

Jawaharlal Institute of Postgraduate Medical Education and Research

(JIPMER), India

Venkatraman Radhakrishnan,

Cancer Institute (WIA), India

*Correspondence: Yu-Qian Sun

sunyuqian83@hotmail.com

Specialty section:

This article was submitted to Alloimmunity and Transplantation,

a section of the journal

Frontiers in Immunology

Received: 06 November 2020

Accepted: 29 December 2020

Published: 16 February 2021

Citation:

Zhou J-R, Shi D-Y, Wei R, Wang Y, Yan C-H, Zhang X-H, XU L-P, Liu K-Y,

Huang $X-J$ and Sun $Y-Q$ (2021) Co-Reactivation of Cytomegalovirus and Epstein-Barr Virus Was Associated With Poor Prognosis After Allogeneic Stem Cell Transplantation.

Front. Immunol. 11:620891.

doi: 10.3389/fimmu.2020.620891

\section{Co-Reactivation of Cytomegalovirus and Epstein-Barr Virus Was Associated With Poor Prognosis After Allogeneic Stem Cell Transplantation}

\author{
Jing-Rui Zhou ${ }^{1}$, Da-Yu Shi ${ }^{1}$, Rong Wei ${ }^{1}$, Yu Wang ${ }^{1,2}$, Chen-Hua Yan ${ }^{1,2}$, \\ Xiao-Hui Zhang ${ }^{1,2}$, Lan-Ping $X^{1,2}$, Kai-Yan Liu ${ }^{1,2}$, Xiao-Jun Huang ${ }^{1,2,3}$ \\ and Yu-Qian Sun ${ }^{1,2 *}$
}

\footnotetext{
1 Peking University People's Hospital, Peking University Institute of Hematology, National Clinical Research Center for Treatment of Hematological Disease, Beijing, China, ${ }^{2}$ Beijing Key Laboratory of Hematopoietic Stem Cell Transplantation for the Treatment of Hematological Diseases, Beijing, China, ${ }^{3}$ Peking-Tsinghua Center for Life Sciences, Beijing, China
}

Reactivation of cytomegalovirus (CMV) or Epstein-Barr virus (EBV) is common after hematopoietic stem cell transplantation (HSCT). Previous researches have demonstrated that either CMV or EBV reactivation is associated with poor outcomes of HSCT. However, few studies investigate the impact of CMV and EBV co-reactivation after HSCT. In this study, we described the clinical characteristics of HSCT recipients with CMV and EBV co-reactivation (defined as CMV and EBV viremia occur at the same period of time). We conducted a longitudinal study of 247 patients who underwent HSCT in our center. A total of 24 (9.7\%) patients had CMV and EBV co-reactivation. These patients showed higher incidence of viral pneumonitis $(\mathrm{P}=0.005)$. Patients with CMV and EBV coreactivation had significant lower 1-year overall survival $(\mathrm{OS})(\mathrm{P}=0.004)$ and lower 1-year leukemia free survival (LFS) ( $P=0.016)$. Our further analysis suggested that duration of CMV $(P=0.014)$, EBV $(P<0.001)$, and $C D 4+C D 25+T$ cell counts at day 30 posttransplantation $(\mathrm{P}=0.05)$ are independent risk factors of virus co-reactivation. In conclusion, patients who developed co-reactivation of CMV and EBV had poor prognosis in terms of lower 1-year OS and LFS, and the CMV and EBV co-reactivation was associated with prolonged CMV or EBV duration and poor CD4+CD25+ T cell reconstitution at day 30 post-transplantation.

Keywords: cytomegalovirus, Epstein-Barr virus, co-reactivation, immune reconstitution, stem cell transplantation

\section{INTRODUCTION}

The burden of clinically relevant viral infections, especially double-stranded DNA herpesviruses, continues to rise. Reactivation of multiple different herpes viruses is commonly acquired following allogeneic hematopoietic stem cell transplantation (HSCT). Cytomegalovirus (CMV) is the most frequently reactivated virus (1) after allo-HSCT and increases non-relapse mortality despite 
the widely adopted protocol of pre-emptive therapy (2-4). Epstein-Barr virus (EBV) (1), especially EBV-related posttransplantation lymphoproliferative disorder (PTLD), is associated with a high mortality rate of 50\%-90\% $(5,6)$.

$\mathrm{CMV}$ and EBV are the most clinically relevant viruses in the present era with well-defined treatment approaches. A bidirectional relationship seems to exist between these two viruses; higher incidence/poor clearance of CMV infection and a higher incidence of EBV-PTLD and delayed immune reconstitution as a cause or effect is key to all these findings ( 7 , 8). It is therefore reasonable to assume that co-reactivation of CMV and EBV may indicate an even more severe clinical condition compared to that for the reactivation of each virus alone. However, few studies have investigated co-reactivation of CMV and EBV among HSCT recipients. In our study, we aimed to explore the clinical characteristics of patients with coreactivation of $\mathrm{CMV}$ and $\mathrm{EBV}$, study the effect of such coreactivation on prognosis, and identify associated risk factors. We also discuss the role of immune reconstitution in the coreactivation of the two viruses.

\section{MATERIALS AND METHODS}

\section{Study Cohort}

A total of 253 patients underwent their first allo-HSCT between July 2015 and June 2016 at Peking University People's Hospital (Haidian district, Beijing) at the Institute of Hematology. These patients were retrospectively reviewed in the current study. The Ethics Committee of Peking University People's Hospital approved this study. All patients provided written informed consent prior to transplantation.

\section{Transplantation Procedure}

For patients with acute leukemia (AL) or myelodysplastic syndrome (MDS) who underwent haplo-HSCT and matched unrelated donor HSCT, the conditioning regimen consisted of cytarabine $\left(4 \mathrm{~g} / \mathrm{m}^{2} /\right.$ day) intravenously on days -10 to -9 , busulfan (3.2 mg/kg/day) intravenously on days -8 to -6 , cyclophosphamide $\left(1.8 \mathrm{~g} / \mathrm{m}^{2} /\right.$ day $)$ intravenously on days -5 to -4 , semustine $(250 \mathrm{mg} /$ $\mathrm{m}^{2}$ ) orally once on day -3 , and rabbit anti-thymocyte globulin (ATG) (2.5 mg/kg/day; Sang Stat, Lyon, France) intravenously on days -5 to -2 . Patients with AL or MDS who underwent HLAidentical HSCT received a conditioning regimen that did not include ATG but consisted of hydroxyurea $(80 \mathrm{mg} / \mathrm{kg}$ ) orally divided twice on day -10 , cytarabine $\left(2 \mathrm{~g} / \mathrm{m}^{2} /\right.$ day $)$ intravenously on day -9 , busulfan $(3.2 \mathrm{mg} / \mathrm{kg} /$ day $)$ intravenously on days -8 to -6 , cyclophosphamide $\left(1.8 \mathrm{~g} / \mathrm{m}^{2} /\right.$ day $)$ intravenously on days -5 to -4 , and semustine $\left(250 \mathrm{mg} / \mathrm{m}^{2}\right)$ orally once on day -3 . For patients with aplastic anemia who underwent haplo-HSCT, conditioning therapy consisted of busulfan ( $3.2 \mathrm{mg} / \mathrm{kg} /$ day) intravenously for 2 days on days -7 and -6 , cyclophosphamide $(50 \mathrm{mg} / \mathrm{kg} /$ day $)$ intravenously for four consecutive days on days -5 to -2 , and rabbit ATG (2.5 mg/kg/day; Sang Stat, Lyon, France) intravenously for four consecutive days on days -5 to -2 (9). For patients with aplastic anemia who underwent identical HSCT or matched unrelated donor HSCT, the conditioning regimen excluded busulfan, and only consisted of cyclophosphamide (50 $\mathrm{mg} / \mathrm{kg} /$ day) intravenously for four consecutive days on days -5 to -2, and rabbit ATG (2.5 mg/kg/day; Sang Stat, Lyon, France) intravenously for four consecutive days on days -5 to -2 . The conditioning regime of the only one MM patient in this study consisted of cytarabine ( $4 \mathrm{~g} / \mathrm{m}^{2} /$ day) on days -10 to -9 , busulfan ( $3.2 \mathrm{mg} / \mathrm{kg} /$ day) on days -10 to -8 , cyclophosphamide $\left(1 \mathrm{~g} / \mathrm{m}^{2} /\right.$ day $)$ on days -7 to -6 , fludarabine $50 \mathrm{mg} /$ day on days -6 to -2 , and simustine $\left(250 \mathrm{mg} / \mathrm{m}^{2}\right)$ orally once on day -3 along with rabbit ATG $(2.5 \mathrm{mg} / \mathrm{kg} /$ day $)$ on days -5 to -2 .

\section{Virus Monitoring and Therapy}

CMV and EBV reactivation was monitored twice per week using real-time quantitative polymerase chain reaction (PCR) of plasma samples. All patients received ganciclovir between days -9 and -2 (10). Pre-emptive therapy with either intravenous ganciclovir (5 mg/kg, twice daily) or intravenous foscarnet $(90 \mathrm{mg} / \mathrm{kg} / \mathrm{d}$ ) was initiated when CMV viremia was confirmed and the treatment lasted until CMV DNA was not detected twice on consecutive tests. Adoptive transfer of CMV-specific cytotoxic T lymphocytes (CTLs) was performed if available in those with refractory CMV infection or CMV disease (2). Antiviral drugs, such as foscarnet, were infused in patients with EBV viremia. In addition, rituximab was infused if EBV viremia was persistent or developed into EBV disease (6). EBV-specific CTL therapy was adopted as salvage option.

\section{Graft-Versus-Host Disease (GVHD) Prophylaxis}

Cyclosporin A (CsA), methotrexate (MTX), and mycophenolate (MMF) were administered to patients for GVHD prophylaxis. CsA was administered at $2.5 \mathrm{mg} / \mathrm{kg} /$ day intravenously in two doses from day -9 until the patients could take CsA orally. The trough concentration of CsA was monitored, requiring a target trough blood concentration of $150-250 \mathrm{ng} / \mathrm{ml}$. MTX was administered intravenously at a dose of $15 \mathrm{mg} / \mathrm{m}^{2}$ on day +1 and $10 \mathrm{mg} / \mathrm{m}^{2}$ on days $+3,+6$, and +11 (day +11 was omitted in patients with matched sibling donor transplantation). Mycophenolate (MMF) was administered orally from day -9 to day +30 at a dose of $0.5 \mathrm{~g}$ ( $0.25 \mathrm{~g}$ for children) every $12 \mathrm{~h}$.

\section{Immunophenotyping}

Peripheral blood samples were collected from recipients on days 30, 60, and 90 after HSCT. The samples were stained without further separation to minimize selective loss shortly after collection. The combinations of the directly conjugated monoclonal antibodies CD3-FITC, CD4-PE, CD8-APC, CD19Per-CP, CD25-PE (BD Biosciences, Mountain View, CA, USA), and their isotype-matched antibodies were used to analyze the immunophenotype of T lymphocyte subsets. Flow cytometry was performed using a BD FACSSort machine (Becton Dickinson Biosciences, San Jose, CA, USA). The data were analyzed using CellQuest software (BD Biosciences).

\section{Definitions}

Myeloid engraftment was defined as the first of three consecutive days with an absolute neutrophil count (ANC) $\geq 0.5 \times 10^{9} / \mathrm{L}$, and 
platelet engraftment was defined as the first of seven consecutive days with a platelet count $\geq 20 \times 10^{9} / \mathrm{L}$ without transfusion. CMV and EBV viremia was defined as the first of two consecutive detections in which virus DNA reached or exceeded 1,000 copies/ml and 500 copies/ml, respectively. Co-reactivation of CMV and EBV was defined as the detection of EBV or CMV viremia during CMV or EBV viremia, respectively. The time of co-reactivation was defined as the day when viremia of the first virus was identified. The duration of viremia was defined as the number of days between the first day of viremia and the first day when the virus was no longer found. The longest duration was included in the analysis of patients with more than one episode of viremia. CMV disease was diagnosed according to the published definition. Both acute and chronic GVHD were diagnosed and graded using traditional criteria $(11,12)$. Time to relapse was defined as days between date of transplantation and date of disease recurrence. Non-relapse mortality (NRM) was defined as death from all causes other than those directly related to a hematologic malignant disease itself, occurring at any time after transplantation. Overall survival (OS) was defined as the number of days from transplantation to death from any cause. Leukemia-free survival (LFS) was defined as the number of days from transplantation to disease progression after transplantation.

\section{Statistical Analyses}

Categorical variables were compared between the two groups using the $\chi^{2}$ test or Fisher's exact test. Continuous variables were compared using a nonparametric test (Mann-Whitney $U$ test). Multivariate Cox proportional hazards models were adopted with proportional hazards assumption and for testing interactions. Statistical analyses were performed using IBM SPSS 22.0 statistical software (IBM SPSS Statistics, USA).

\section{RESULTS}

\section{Patients Characteristics}

Six patients infected with EBV were excluded from the study. Finally, 247 patients were enrolled in this study. Patient characteristics are listed in Table 1. There were 144 (58.3\%) men. The median age was 29 (1-63) years. Acute leukemia, both

TABLE 1 | Characteristics of patients.

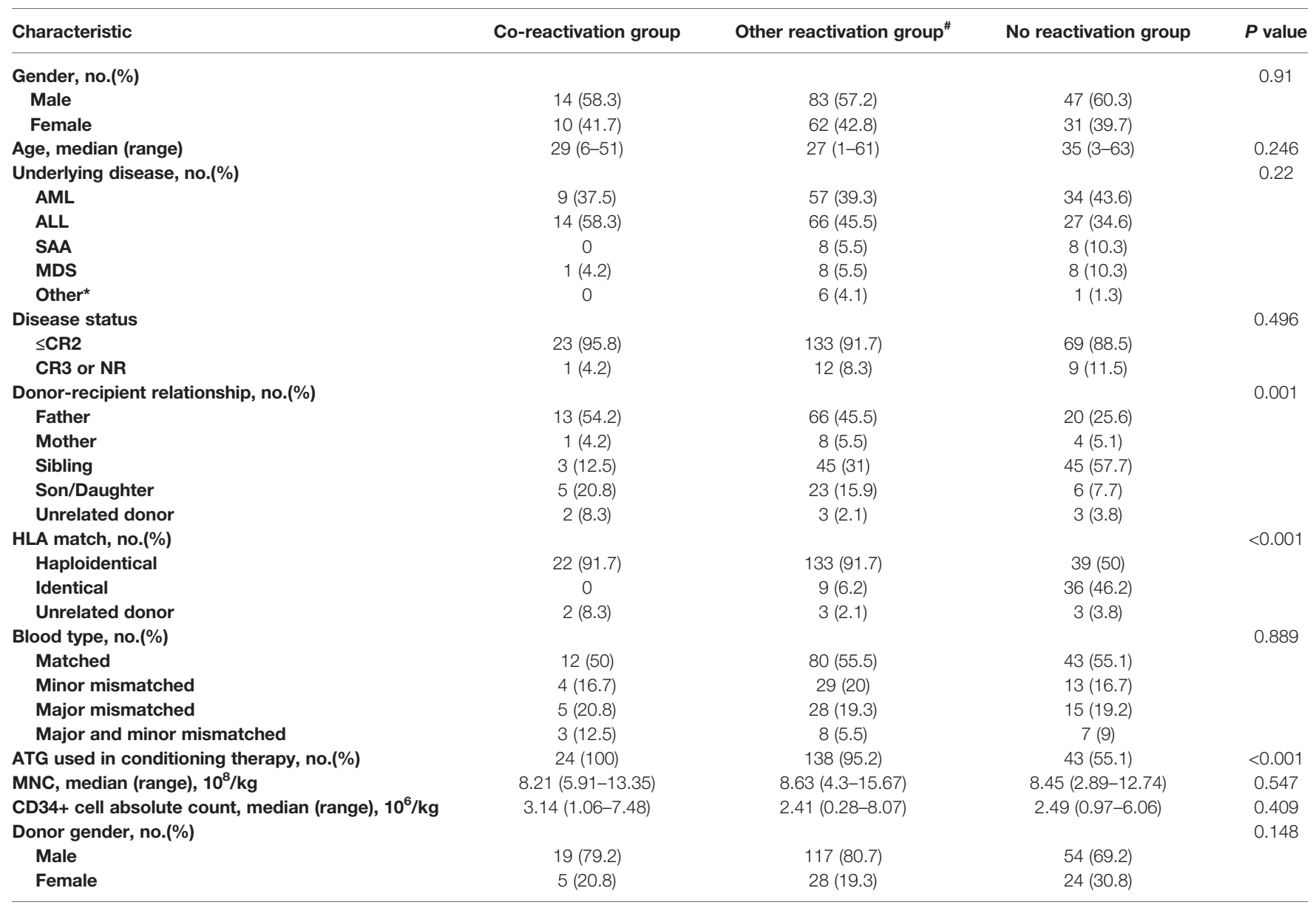

"Other reactivation group includes reactivation of CMV only, and reactivation of both CMV and EBV but does not fulfill definition of CMV and EBV co-reactivation ${ }^{*}$ Other underlying diseases include multiple myeloma (one patient), chronic myelomonocytic leukemia (two patients), chronic myeloid leukemia (two patients), acute heterozygosis leukemia (two patients). 
acute myeloid leukemia $(n=100,40.5 \%)$ and acute lymphoblastic leukemia ( $\mathrm{n}=107,43.3 \%)$, accounted for most patients. More than half $(n=194,78.5 \%)$ of patients underwent HSCT from haploidentical donors. Forty-five (18.2\%) patients received HSCT from HLA-matched siblings, and eight (3.2\%) underwent HSCT from unrelated donors. Myeloid engraftment and platelet engraftment were achieved in $245(99.2 \%)$ patients at a median of 13 (10-31) days and in 227 (91.9\%) patients at a median of 14 (6267) days after HSCT, respectively. The incidence of grade 3-4 acute GVHD and grade 1-4 acute GVHD was $6.12 \%(n=15)$ and $50.6 \%(n=125)$, respectively. The median follow-up time for survivors was 12 months. The 1-year OS, LFS, NRM, and relapse rates were $67.6 \%, 66.0 \%, 19.4 \%$, and $6.5 \%$, respectively.

\section{Virus Reactivation}

At least one episode of CMV viremia was found in $68.4 \%$ of the patients $(n=169)$, among which 15 patients were infected twice or more during the year after transplantation. The median onset time of CMV viremia was 34 (7-175) days, and the median duration was 20 days (range, 6-77 days). CMV DNA copy numbers varied in patients with a median of $5.48 \times 10^{3}$ $\left(0-5.01 \times 10^{5}\right)$ copies. Thirty-six $(14.6 \%)$ patients had EBV reactivation. EBV viremia occurred at a median of 48.5 (25102) days after transplantation and lasted a median of 14 (3-60) days. For patients with reactivated EBV, EBV DNA copies reached $6 \times 10^{3}\left(6 \times 10^{2}-1.76 \times 10^{6}\right)$. According to the definition above, $24(9.7 \%)$ patients were categorized as having coreactivation of $\mathrm{CMV}$ and $\mathrm{EBV}$. Twelve (4.9\%) patients had both CMV and EBV reactivation but did not fulfill the definition of co-reactivation. A total of 133 (53.8\%) patients were infected with CMV only, and 78 (31.6\%) patients had no episodes of reactivation of either virus.

\section{Effect of CMV and EBV Co-Reactivation on Clinical Outcomes}

Patients were divided into three groups based on CMV and EBV reactivation according to our definition above: (1) coreactivation group, defined as the detection of EBV or CMV viremia during CMV or EBV viremia, respectively; (2) other reactivation group was defined as reactivation with $\mathrm{CMV}$ and/or EBV but did not meet the criteria for co-reactivation; and (3) no reactivation group was defined as neither CMV nor EBV reactivation detected. The characteristics of the three groups are listed in Table $\mathbf{1 .}$

Myeloid engraftment was comparable between the three groups $(100 \%$ vs. $100 \%$ vs. $97.4 \%$ for co-reactivation, other reactivation, and no reactivation groups, respectively, $P=0.113$ ). However, myeloid engraftment seemed to be delayed in patients with no virus reactivation (13 vs. 13 vs. 14 days for coreactivation, other reactivation, and no reactivation groups, respectively, $P=0.008)$. Regarding platelet engraftment, the proportion of patients $(87.5 \%$ vs. $91.7 \%$ vs. $93.6 \%$ for coreactivation, other reactivation, and no reactivation groups, respectively, $P=0.628$ ) and days of engraftment ( 13 vs. 13 vs. 14 for co-reactivation, other reactivation, and no reactivation groups, respectively, $P=0.389$ ) were comparable between the three groups. The incidence of acute GVHD was significantly higher in the reactivation group than in the no reactivation group ( $50 \%$ vs. $66.9 \%$ vs. $20.5 \%$, respectively, $P<0.001$ ), while the incidence of chronic GVHD was similar in the three groups ( $4.2 \%$ vs. $9.7 \%$ vs. $9 \%$ for co-reactivation, other reactivation, and no reactivation groups, respectively, $P=0.682$ ). Patients in the reactivation group were more likely to develop viral pneumonia than those in the other two groups $(20.8 \%$ vs $9 \%$ vs $1.3 \%$ for coreactivation, other reactivation, and no reactivation groups, respectively, $P=0.005)$, but we did not observe a similar trend for viral enteritis ( $0 \%$ vs $2.1 \%$ vs. $0 \%$ for co-reactivation, other reactivation, and no reactivation groups, respectively, $P=0.344$ ). CMV or EBV disease was diagnosed in 22 patients, among whom there were 19 cases of pneumonia and three cases of gastroenteritis. EBV-PTLD was diagnosed in 5 patients, and all 5 patients received rituximab treatment. Hemorrhagic cystitis was also more prevalent in the reactivation group $(37.5 \%$ vs. $35.2 \%$ vs. $14.1 \%$ for co-reactivation, other reactivation, and no reactivation groups, respectively, $P=0.002$ ) (Table 2 ).

The 1-year OS was significantly lower in the reactivation group (50\% vs. $66.2 \%$ vs.75.6\% for co-reactivation, other reactivation, and no reactivation groups, respectively, $P=0.021$ ). The 1-year LFS was also lower in the co-reactivation group (50\% vs. $65.5 \%$ vs. $71.8 \%$ for co-reactivation, other reactivation, and no reactivation groups, respectively), although the difference was not statistically significant $(P=0.057)$. Viral reactivation was an independent risk factor for 1-year OS (Figure 1) (HR 4.94 for coreactivation vs. no reactivation, and $\mathrm{HR} 1.94$ for other reactivation vs. no reactivation, $\mathrm{P}=0.004$ ) and LFS (Figure 2) (HR 3.66 for co-reactivation vs. no reactivation, and HR 1.51 for other reactivation vs. no reactivation, $\mathrm{P}=0.016$ ). The causes of death are summarized in Supplementary Table S1. Risk factors for 1-year OS and 1-year LFS are summarized in Table 3.

\section{Predictive Factors Associated With CMV and EBV Co-Reactivation}

Patients with CMV and EBV co-reactivation were compared with all other patients to identify factors associated with coreactivation. The donor-recipient relationship (father, mother, sibling, and son/daughter, respectively, vs. unrelated donor); HLA matched status, use of ATG; period of CMV and EBV viremia, respectively; and peak CMV and EBV DNA copies, respectively, were associated with $\mathrm{CMV}$ and $\mathrm{EBV}$ coreactivation. $\mathrm{CD} 3+(P=0.052)$ and $\mathrm{CD} 4+\mathrm{CD} 25+(P=0.052)$ cell counts on day 30 after transplantation also seemed to play a role in virus co-reactivation in univariate analysis. Cox multivariate analysis of the above factors showed that the donor-recipient relationship (father, mother, sibling, and son/daughter, respectively, vs. unrelated donor, $P=0.001)$, duration of $\mathrm{CMV}$ $(P=0.014)$ and EBV $(P<0.001)$, and CD4+CD25+ cell counts at day 30 post-transplantation $(P=0.05)$ were independent risk factors for CMV and EBV co-reactivation (Table 4). However, of all 247 patients enrolled in the study, 45 (18.2\%) patients received HSCT from HLA-matched family donors and all of these donors were siblings, which might introduce a potential bias. To account for this, we reanalyzed patients who received 
TABLE 2 | The impact of co-reactivation on clinical outcomes.

\begin{tabular}{|c|c|c|c|c|}
\hline Clinical Outcomes & Co-reactivation group & Other reactivation group $\#$ & No reactivation group & $P$ value \\
\hline neutrophil engraftment, no.(\%) & $24(100)$ & $145(100)$ & $76(97.4)$ & 0.113 \\
\hline Time of neutrophil engraftment, $+d$, median (range) & $13(10-20)$ & $13(10-31)$ & $14(10-24)$ & 0.008 \\
\hline Platelet engraftment, no.(\%) & $21(87.5)$ & $133(91.7)$ & 73 (93.6) & 0.628 \\
\hline Time of PLT engraftment, +d, median (range) & $13(9-56)$ & $14(6-267)$ & $14(7-80)$ & 0.389 \\
\hline aGVHD, no. (\%) & $12(50)$ & $97(66.9)$ & $16(20.5)$ & $<0.001$ \\
\hline Time of aGVHD, $+\mathrm{d}$, median (range) & $23(9-57)$ & $19(6-87)$ & $14.5(9-40)$ & $<0.001$ \\
\hline aGVHD grade, no (\%) & & & & 0.015 \\
\hline $0-11$ & $23(95.8)$ & $131(90.3)$ & $78(100)$ & \\
\hline III-IV & $1(4.2)$ & $14(9.7)$ & $0(0)$ & \\
\hline CMV viremia, no. (\%) & $24(100)$ & $145(100)$ & $0(0)$ & -- \\
\hline Time of first $\mathrm{CMV}$ viremia, $+\mathbf{d}$, median (range) & $33.5(21-62)$ & $34(7-175)$ & -- & -- \\
\hline Duration of CMV viremia, $\mathrm{d}$, median (range) & $23.5(14-56)$ & $18(6-77)$ & -- & -- \\
\hline Receiving CMV-CTL & $13(54.2 \%)$ & $12(8.2 \%)$ & 0 & $<0.001$ \\
\hline Highest CMV viral load, $\times 10^{3}$ copies $/ \mathrm{ml}$, median (range) & $28.25(4.16-206)$ & $9.08(1.12-501)$ & -- & -- \\
\hline EBV viremia, no. (\%) & $24(100)$ & $12(8.3)$ & $0(0)$ & -- \\
\hline Time of first EBV viremia, +d, median (range) & $45.5(25-76)$ & $58.5(35-102)$ & -- & -- \\
\hline Duration of EBV viremia, d, median (range) & $15.5(3-39)$ & $14(4-60)$ & -- & -- \\
\hline Highest EBV viral load, $\times 10^{3}$ copies $/ \mathrm{ml}$, median (range) & $6.75(1.2-1760)$ & $5.04(0.6-536)$ & -- & -- \\
\hline Viral pneumonitis, no. (\%) & $5(20.8)$ & $13(9)$ & 1 (1.3)\# & 0.005 \\
\hline Viral enteritis, no. (\%) & $0(0)$ & $3(2.1)$ & $0(0)$ & 0.344 \\
\hline Hemorrhagic cystitis, no. (\%) & $9(37.5)$ & $51(35.2)$ & $11(14.1)$ & 0.002 \\
\hline cGVHD, no. (\%) & $1(4.2)$ & $14(9.7)$ & $7(9)$ & 0.682 \\
\hline \multicolumn{5}{|l|}{ Immune reconstitution at day 30 after $\mathrm{HSCT}$, median (range) } \\
\hline WBC, $10^{9} / \mathrm{L}$ & $5.24(2.55-24.33)$ & $5.49(1.49-30.9)$ & $4.73(1.44-19.08)$ & 0.311 \\
\hline CD19, $10^{\circ} / \mathrm{L}$ & $0.0052(0.039)$ & $0.0034(0.24)$ & $0.0041(0.042)$ & 0.505 \\
\hline CD3, $10^{9} / \mathrm{L}$ & $0.018(1.66)$ & $0.088(7.69)$ & $0.18(3.02)$ & 0.009 \\
\hline CD4, $10^{9} / \mathrm{L}$ & $0.0031(0.21)$ & $0.012(0.56)$ & $0.072(0.68)$ & $<0.001$ \\
\hline CD8, $10^{9} / \mathrm{L}$ & $0.011(1.47)$ & $0.056(7.28)$ & $0.074(2.46)$ & 0.086 \\
\hline CD4CD25, $10^{9} / \mathrm{L}$ & $0.00045(0.029)$ & $0.0017(0.19)$ & $0.0083(0.27)$ & $<0.001$ \\
\hline WBC count at day 60 post-transplantation, median (range) & $3.09(0.6-7.76)$ & $3.41(0.65-15.77)$ & $4.2(0.53-9.96)$ & 0.203 \\
\hline Overall survival in 1 year after HSCT no. (\%) & $12(50)$ & $96(66.2)$ & $59(75.6)$ & 0.021 \\
\hline Leukemia free survival in 1 year after HSCT no. (\%) & $12(50)$ & $95(65.5)$ & $56(71.8)$ & 0.057 \\
\hline \multicolumn{5}{|l|}{ Mortality cause, no. (\%) } \\
\hline NRM & $9(37.5)$ & $27(18.6)$ & $12(15.4)$ & 0.053 \\
\hline Relapse & $0(0)$ & $11(7.59)$ & $1(1.28)$ & 0.057 \\
\hline Relapse time, d, median (range) & -- & $118(60-359)$ & $224(55-364)$ & 0.262 \\
\hline
\end{tabular}

"One patient who did not have CMV and EBV viremia was highly suspicious of EBV pneumonitis because of a positive EBV-DNA result in bronchoalveolar lavage fluid.

haplo-HSCT. The donor-recipient relationship was excluded as a risk factor for $\mathrm{CMV}$ and $\mathrm{EBV}$ co-reactivation in univariate analysis $(P=0.561)$.

\section{DISCUSSION}

In this study, we demonstrated that patients with CMV and EBV co-reactivation were associated with poor prognosis in terms of acute GVHD, viral disease, OS, and LFS. This suggests that our study has important implications for clinical physicians.

Although CMV reactivation was strongly associated with EBV reactivation (13), co-reactivation of CMV and EBV was relatively less common than that of other double-stranded DNA viruses. Twenty-four (9.7\%) patients were identified as having CMV and EBV co-reactivation in our study. This is consistent with a previous study in which $32 / 330(9.7 \%)$ patients had coreactivation of CMV and EBV (14), although the definition of virus co-reactivation was slightly different, as our study emphasized that the two viruses must be present at the same time. Hill et al. showed that $62 \%$ of patients could be detected with $\geq 2$ double-stranded viruses after allogeneic HSCT. However, only $2.4 \%$ of patients were found to have CMV and $\mathrm{EBV}$, with or without other double-stranded viruses (1).

Our study found that CMV and EBV co-reactivation was associated with decreased 1-year OS, which was mainly due to increased NRM. In the co-reactivation group, the 1-year NRM was higher than in the other two groups, although the difference was not statistically significant $(P=0.053)$, and no death occurred because of relapse. This was partly in accordance with a previous study in which patients with CMV and EBV co-reactivation had a significant higher 6-month non-relapse mortality than those with CMV or EBV reactivation alone (14). Although CMV reactivation alone after HSCT was not associated with 1-year OS because of the decreased relapse and increased 1-year NRM (7), co-reactivation with EBV was different.

Prolonged viremia with higher CMV-load was observed in the co-reactivation group than in the other-reactivation group, reflecting the influence of parallel EBV-reactivation on CMVreplication and kinetics, which is commonly seen amongst the $\beta$ herpesviruses as they can regulate immunity. Immunoreactivation of one virus by another virus has been documented previously by 


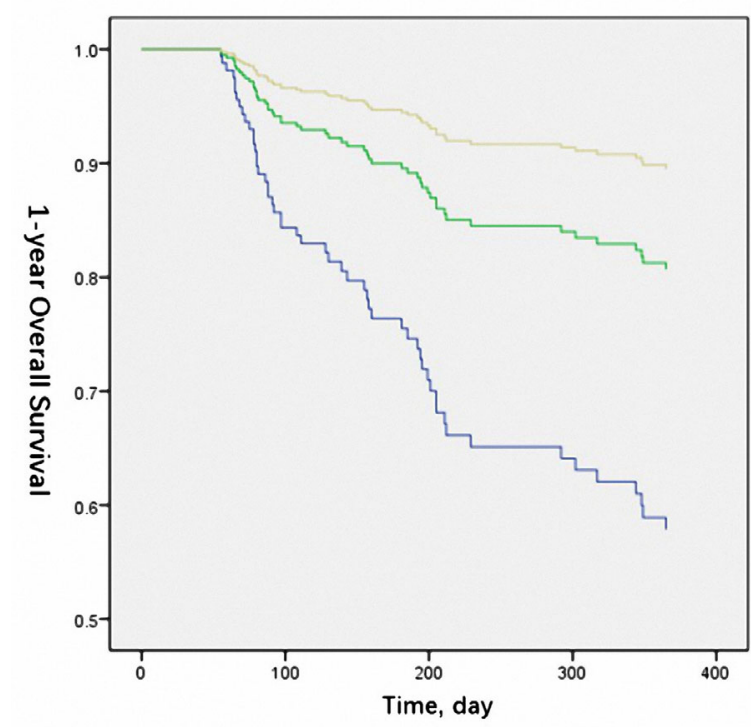

CMV and EBV

co-reactivation

$\checkmark$ Co-reactivation group

$\checkmark$ Other reactivation group

No reactivation group

FIGURE 1 Cytomegalovirus (CMV) and Epstein-Barr virus (EBV) co-reactivation was identified as one of the independent risk factors for 1-year overall survival. $(P=0.004)$.

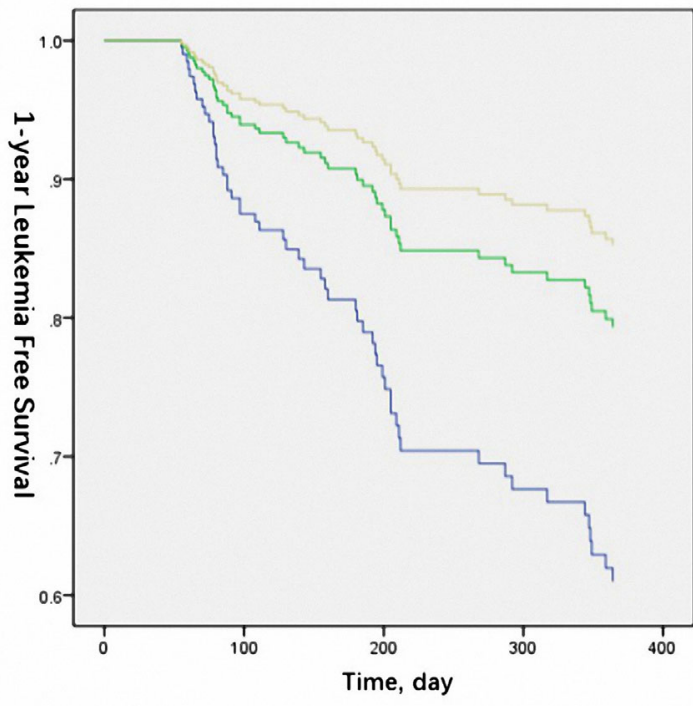

CMV and EBV co-reactivation

$\rightarrow$ Co-reactivation group

$\neg$ Other reactivation group

No reactivation group

FIGURE 2 | Cytomegalovirus (CMV) and Epstein-Barr virus (EBV) co-reactivation was identified as one of the independent risk factors for 1-year leukemia free survival. $(\mathrm{P}=0.016)$.

us and others in both HSCT and SOT. This could also reflect the poor immune reconstitution as reflected in poor CD3+ and CD4 $+25+$ cell counts (on day 30 ), which were lower than those in the other reactivation and no reactivation groups.

The incidence of acute GVHD was significantly higher in the co-reactivation and other reactivation groups than in the no reactivation group in our study. Patients in both groups had reactivated $\mathrm{CMV}$, indicating an association between $\mathrm{CMV}$ and acute GVHD. In fact, multiple studies have shown that acute GVHD and its treatment put patients at risk of CMV reactivation $(15,16)$. A retrospective study also identified CMV reactivation as a risk factor for acute GVHD, proving the bidirectional 
TABLE 3 | Risk factors for 1-year OS and 1-year LFS.

\begin{tabular}{|c|c|c|c|c|c|c|}
\hline \multirow[t]{3}{*}{ Factors } & \multicolumn{2}{|c|}{ Univariate analysis } & \multicolumn{4}{|c|}{ Multivariate analysis } \\
\hline & \multirow{2}{*}{$\begin{array}{l}\text { OS } \\
\text { P value }\end{array}$} & \multirow{2}{*}{$\begin{array}{l}\text { LFS } \\
\text { P value }\end{array}$} & \multicolumn{2}{|r|}{ os } & \multicolumn{2}{|r|}{ LFS } \\
\hline & & & $\begin{array}{c}\mathbf{P} \\
\text { value }\end{array}$ & HR $[95 \% \mathrm{Cl}]$ & $\begin{array}{c}P \\
\text { value }\end{array}$ & HR $[95 \% \mathrm{Cl}]$ \\
\hline Underlying disease & 0.037(ALL vs. MDS) & $\begin{array}{c}0.04 \text { (ALL vs. } \\
\text { SAA) } \\
0.028(A L L \text { vs. } \\
\text { MDS) } \\
0.087(A M L \\
\text { vs.MDS) }\end{array}$ & $\mathrm{N}$ & -- & $N$ & -- \\
\hline Disease status ( CR3 or NR vs. CR1-2) & $<0.001$ & $<0.001$ & $<0.001$ & $\begin{array}{c}6.045 \\
(3.088-11.832)\end{array}$ & $<0.001$ & $\begin{array}{c}5.685 \\
(2.984-10.832)\end{array}$ \\
\hline HLA match & $\begin{array}{c}0.05 \\
\text { (matched sibling vs. haploidentical } \\
\text { donor) }\end{array}$ & $\mathrm{N}$ & $\mathrm{N}$ & -- & $\mathrm{N}$ & -- \\
\hline $\begin{array}{l}\text { Platelet engraftment }(<=\text { median versus } \\
>\text { median) }\end{array}$ & $<0.001$ & $<0.001$ & $<0.001$ & $\begin{array}{c}0.103 \\
(0.052-0.205)\end{array}$ & $<0.001$ & $\begin{array}{c}0.107 \\
(0.054 s-0.210)\end{array}$ \\
\hline aGVHD grade (0-II vs. III-IV) & $<0.001$ & $<0.001$ & $\mathrm{~N}$ & -- & $\mathrm{N}$ & -- \\
\hline $\begin{array}{l}\text { Virus reactivation (no reactivation vs. Co- } \\
\text { reactivation) }\end{array}$ & 0.021 & 0.057 & 0.001 & $\begin{array}{c}0.202 \\
(0.078-0.527)\end{array}$ & 0.005 & $\begin{array}{c}0.274 \\
(0.112-0.671)\end{array}$ \\
\hline Viral pneumonitis & $<0.001$ & $<0.001$ & $\mathrm{~N}$ & -- & $\mathrm{N}$ & -- \\
\hline Hemorrhagic cystitis & 0.002 & 0.002 & $\mathrm{~N}$ & -- & $\mathrm{N}$ & -- \\
\hline $\begin{array}{l}\text { Highest viral load of } \mathrm{CMV}((>\text { median versus }<= \\
\text { median) })\end{array}$ & 0.004 & 0.006 & $\mathrm{~N}$ & -- & $\mathrm{N}$ & -- \\
\hline $\begin{array}{l}\text { WBC count at day } 60 \text { (>median versus }<= \\
\text { median) }\end{array}$ & 0.001 & 0.001 & 0.005 & $\begin{array}{c}0.851 \\
(0.734-0.988)\end{array}$ & 0.034 & $\begin{array}{c}0.857 \\
(0.743-0.988)\end{array}$ \\
\hline
\end{tabular}

$N$, not statistically significant.

TABLE 4 | Risk factors for cytomegalovirus (CMV) and Epstein-Barr virus (EBV) co-reactivation.

\begin{tabular}{|c|c|c|c|}
\hline \multirow[t]{2}{*}{ Factors } & \multirow{2}{*}{$\begin{array}{c}\text { Univaraite analysis } \\
\text { P value }\end{array}$} & \multicolumn{2}{|c|}{ Multivariate analysis } \\
\hline & & $P$ value & HR $[95 \% \mathrm{Cl}]$ \\
\hline Donor-recipient relationship & $\begin{array}{c}0.013 \text { (sibling vs. father) } \\
0.019 \text { (sibling vs. son/daughter) } \\
0.009 \text { (sibling vs. unrelated matched } \\
\text { donor) }\end{array}$ & $\begin{array}{c}0.001^{\#} \\
<0.001 \text { (unrelated matched donor } \\
\text { vs. father) } \\
0.005 \text { (unrelated matched donor } \\
\text { vs. } \\
\text { sibling) }\end{array}$ & $\begin{array}{c}131.479(13.236- \\
1306.056) \\
35.809(2.966- \\
432.346)\end{array}$ \\
\hline HLA match & $\begin{array}{l}0.02 \text { (identical sibling vs. unrelated } \\
\text { matched donor) }\end{array}$ & -- & -- \\
\hline ATG used in conditioning therapy & 0.022 & $\mathrm{~N}$ & -- \\
\hline Duration of CMV viremia (<=median versus $>$ median) & $<0.001$ & 0.014 & $1.040(1.008-1.073)$ \\
\hline Duration of EBV viremia (<=median versus >median) & $<0.001$ & $<0.001$ & $1.155(1.108-1.205)$ \\
\hline Highest viral load of CMV (<=median versus $>$ median) & $<0.001$ & $\mathrm{~N}$ & -- \\
\hline Highest viral load of EBV (<=median versus $>$ median) & $<0.001$ & $N$ & -- \\
\hline $\begin{array}{l}\text { CD } 3+\text { cell counts at day } 30 \text { post-transplantation }(<=\text { median } \\
\text { versus }>\text { median) }\end{array}$ & 0.052 & $\mathrm{~N}$ & -- \\
\hline CD4+CD25+ cell counts at day 30 post-transplantation & 0.052 & 0.05 & $0(0-0.8)$ \\
\hline
\end{tabular}

(<=median versus >median)

\#Donor-recipient relationship as an independent risk factor for virus co-reactivation was believed to be affected by HLA match as siblings contained all cases of HLA-identical HSCT. Reanalysis of haplo-identical HSCT patients further confirmed this hypothesis.

relationship between CMV reactivation and acute GVHD (17). A previous study also identified grade III-IV acute GVHD as a risk factor for EBV reactivation (18). However, CMV and EBV coreactivation in our study was not associated with a higher incidence of overall acute GVHD or severe acute GVHD (grade III-IV) than that in the other reactivation group. It might be that the other reactivation group also included patients with both reactivated CMV and EBV. However, they were not reactivated at the same period of time.

The independent risk factors for co-reactivation of CMV and EBV virus identified in this study include duration of CMV and $\mathrm{EBV}, \mathrm{CD} 4+\mathrm{CD} 25+\mathrm{T}$ cell counts on day 30 post-transplantation, 
and donor-recipient relationship. Reanalysis of haplo-HSCT patients was performed to account for the role of donorrecipient relationship on virus co-reactivation. As a result, the donor-recipient relationship was excluded in the univariate analysis $(P=0.561)$. Previous studies have shown that risk factors for CMV reactivation after HSCT include a donor or recipient seropositive for $\mathrm{CMV}$, mismatched or unrelated donors, pre-allo-HSCT viremia, and use of alemtuzumab (19, 20). However, almost all patients in our study were either donor seropositive or recipient seropositive, making it less meaningful to analyze the effect of serum status on virus reactivation.

Our study identified CD4+CD25+ cell counts on day 30 postHSCT as an independent risk factor for CMV and EBV coreactivation. $\mathrm{CD} 4+\mathrm{CD} 25+\mathrm{T}$ cells are a subset of $\mathrm{CD} 4+\mathrm{T}$ cells and represent regulatory $\mathrm{T}$ cells (Tregs). Normally, Tregs play an important role in controlling the cellular immune response to infectious agents, providing a balance to activating stimuli that allow elimination of the pathogen without immunopathological damage to the host. As a result, patients with a viral infection usually have an elevated number of Tregs to control the cellular immune response. However, one study showed that no significant difference could be detected by comparing both absolute and relative Treg cell numbers among allogeneic HSCT patients with and without CMV infection, indicating that Tregs did not inhibit CMV clearance in HSCT patients (21). Moreover, Ngoma et al. showed that a lower proportion of Treg on day 30 after allogeneic HSCT was associated with an increased risk of CMV infection, implying an association between impaired Treg reconstitution and CMV infection (22). The paradox might be due to the positive correlation between Treg and CMV-specific CD8+ T cell recovery after HSCT (23). Although Tregs were activated at an early stage in EBV infection (24), our study demonstrated that the effect of decreased Treg numbers on CMV reactivation was greater than that of elevated Treg numbers on EBV reactivation, as the co-reactivation group had significantly lower CD4+CD25+ cell counts.

The present study has several limitations. First, the retrospective nature of this study has inherent risks of bias; however, the patient profile and the transplant complications do not appear different from those reported in prospective studies. Second, we did not monitor other herpesviruses, which could have a bearing on all these findings. However, we concentrated only on the two most clinically important viruses with defined treatment options. We did not monitor lymphocyte reconstitution, especially virus-specific immune reconstitution, or the replication kinetics of the viruses, which could be important in managing and understanding these situations better.

Despite several limitations, we have demonstrated in this study that co-reactivation of CMV and EBV according to our definition

\section{REFERENCES}

1. Hill JA, Mayer BT, Xie H, Leisenring WM, Huang ML, Stevens-Ayers T, et al. The cumulative burden of double-stranded DNA virus detection after allogeneic HCT is associated with increased mortality. Blood (2017) 129 (16):2316-25. doi: 10.1182/blood-2016-10-748426 is associated with lower 1-year OS and LFS. CD4+CD25+ T cell counts on day 30 post-transplantation are identified as one of the independent risk factors for CMV and EBV co-reactivation, which may provide an alternative way to prevent CMV and EBV reactivation in HSCT patients.

\section{DATA AVAILABILITY STATEMENT}

The raw data supporting the conclusions of this article will be made available by the authors, without undue reservation.

\section{ETHICS STATEMENT}

The studies involving human participants were reviewed and approved by The Ethics Committee of the Peking University People's Hospital. Written informed consent to participate in this study was provided by the participants' legal guardian/next of kin.

\section{AUTHOR CONTRIBUTIONS}

$\mathrm{X}-\mathrm{JH}$ and Y-QS designed the study. J-RZ, D-YS, RW and Y-QS wrote the manuscript. All authors contributed to the data preparation and interpretation. All authors approved the final version. All authors contributed to the article and approved the submitted version.

\section{FUNDING}

This study was supported by the Beijing Municipal Science \& Technology Commission (No. Z19110000661905), National Natural Science Foundation of China (Grant No. 81600103).

\section{ACKNOWLEDGMENTS}

We would like to give special thanks to Dr. Ranjit Kumar Sahoo for his constructive comments.

\section{SUPPLEMENTARY MATERIAL}

The Supplementary Material for this article can be found online at: https://www.frontiersin.org/articles/10.3389/fimmu.2020. 620891/full\#supplementary-material

2. Liu J, Kong J, Chang YJ, Chen H, Chen YH, Han W, et al. Patients with refractory cytomegalovirus (CMV) infection following allogeneic haematopoietic stem cell transplantation are at high risk for CMV disease and non-relapse mortality. Clin Microbiol Infect (2015) 21(12):1121 e9-15. doi: 10.1016/j.cmi.2015.06.009

3. Tomblyn M, Chiller T, Einsele H, Gress R, Sepkowitz K, Storek J, et al. Guidelines for preventing infectious complications among hematopoietic cell 
transplantation recipients: a global perspective. Biol Blood Marrow Transplant (2009) 15(10):1143-238. doi: 10.1016/j.bbmt.2009.06.019

4. Green ML, Leisenring W, Xie H, Mast TC, Cui Y, Sandmaier BM, et al. Cytomegalovirus viral load and mortality after haemopoietic stem cell transplantation in the era of pre-emptive therapy: a retrospective cohort study. Lancet Haematol (2016) 3(3):e119-27. doi: 10.1016/S2352-3026(15) 00289-6

5. Styczynski J, Gil L, Tridello G, Ljungman P, Donnelly JP, van der Velden W, et al. Response to rituximab-based therapy and risk factor analysis in Epstein Barr Virus-related lymphoproliferative disorder after hematopoietic stem cell transplant in children and adults: a study from the Infectious Diseases Working Party of the European Group for Blood and Marrow Transplantation. Clin Infect Dis (2013) 57(6):794-802. doi: 10.1093/cid/ cit391

6. Xu LP, Zhang C-L, Mo X-D, Zhang X-H, Chen H, Han W, et al. Epstein-Barr Virus-Related Post-Transplantation Lymphoproliferative Disorder after Unmanipulated Human Leukocyte Antigen Haploidentical Hematopoietic Stem Cell Transplantation: Incidence, Risk Factors, Treatment, and Clinical Outcomes. Biol Blood Marrow Transplant (2015) 21(12):2185-91. doi: $10.1016 /$ j.bbmt.2015.07.035

7. Green ML, Leisenring WM, Xie H, Walter RB, Mielcarek M, Sandmaier BM, et al. CMV reactivation after allogeneic HCT and relapse risk: evidence for early protection in acute myeloid leukemia. Blood (2013) 122(7):1316-24. doi: 10.1182/blood-2013-02-487074

8. Rouce RH, Louis CU, Heslop HE. Epstein-Barr virus lymphoproliferative disease after hematopoietic stem cell transplant. Curr Opin Hematol (2014) 21 (6):476-81. doi: 10.1097/MOH.0000000000000083

9. Xu LP, Liu KY, Liu DH, Han W, Chen H, Chen YH, et al. A novel protocol for haploidentical hematopoietic SCT without in vitro T-cell depletion in the treatment of severe acquired aplastic anemia. Bone Marrow Transplant (2012) 47(12):1507-12. doi: 10.1038/bmt.2012.79

10. Huang XJ, Liu DH, Liu KY, Xu LP, Chen H, Han W, et al. Treatment of acute leukemia with unmanipulated HLA-mismatched/haploidentical blood and bone marrow transplantation. Biol Blood Marrow Transplant (2009) 15 (2):257-65. doi: 10.1016/j.bbmt.2008.11.025

11. Przepiorka D, Weisdorf D, Martin P, Klingemann HG, Beatty P, Hows J, et al. 1994 Consensus Conference on Acute GVHD Grading. Bone Marrow Transplant (1995) 15(6):825-8.

12. Glucksberg H, Storb R, Fefer A, Buckner CD, Neiman PE, Clift RA, et al. Clinical manifestations of graft-versus-host disease in human recipients of marrow from HL-A-matched sibling donors. Transplantation (1974) 18 (4):295-304. doi: 10.1097/00007890-197410000-00001

13. Zallio F, Primon V, Tamiazzo S, Pini M, Baraldi A, Corsetti MT, et al. EpsteinBarr virus reactivation in allogeneic stem cell transplantation is highly related to cytomegalovirus reactivation. Clin Transplant (2013) 27(4):E491-7. doi: $10.1111 /$ ctr.12172

14. Song T, Chen G, Zhang X, Xu Y, Chen J, Wang Y, et al. Clinical outcomes of allogeneic hematopoietic stem cell transplantation patients with co-activation of cytomegalovirus and Epstein-Barr virus. Zhonghua Yi Xue Za Zhi (2014) 94 (40):3135-9.
15. Nathan Cantoni HHH, Khanna N, Gerull S, Buser A, Bucher C, Halter J, et al. Risk Factors For The Development Of Cytomegalovirus Disease After Allogeneic Stem Cell Transplantation. Haematologica (2006) 9(1):78-83.

16. Miller W, Flynn P, McCullough J, Balfour HH, Goldman A, Haake R, et al. Cytomegalovirus infection after bone marrow transplantation: an association with acute graft-v-host disease. Blood (1986) 674(4).

17. Cantoni N, Hirsch HH, Khanna N, Gerull S, Buser A, Bucher C, et al. Evidence for a bidirectional relationship between cytomegalovirus replication and acute graft-versus-host disease. Biol Blood Marrow Transplant (2010) 16 (9):1309-14. doi: 10.1016/j.bbmt.2010.03.020

18. Juvonen E, Aalto S, Tarkkanen J, Volin L, Hedman K, Ruutu T. Retrospective evaluation of serum Epstein Barr virus DNA levels in 406 allogeneic stem cell transplant patients. Haematologica (2007) 96(6):819-25. doi: 10.3324/ haematol.10751

19. Sousa H, Boutolleau D, Ribeiro J, Teixeira AL, Pinho Vaz C, Campilho F, et al. Cytomegalovirus infection in patients who underwent allogeneic hematopoietic stem cell transplantation in Portugal: a five-year retrospective review. Biol Blood Marrow Transplant (2014) 20(12):1958-67. doi: 10.1016/j.bbmt.2014.08.010

20. Rustia E, Violago L, Jin Z, Foca MD, Kahn JM, Arnold S, et al. Risk Factors and Utility of a Risk-Based Algorithm for Monitoring Cytomegalovirus, Epstein-Barr Virus, and Adenovirus Infections in Pediatric Recipients after Allogeneic Hematopoietic Cell Transplantation. Biol Blood Marrow Transplant (2016) 22(9):1646-53. doi: 10.1016/j.bbmt.2016.05.014

21. Velaga S, Ukena SN, Höpting M, Ivanyi P, Borchers S, Mischak-Weissinger $\mathrm{E}-\mathrm{M}$, et al. Reconstitution and phenotype of Tregs in CMV reactivating patients following allogeneic hematopoietic stem cell transplantation. Immunol Invest (2013) 42(1):18-35. doi: 10.3109/08820139.2012.719563

22. Ngoma AM, Ikeda K, Hashimoto Y, Mochizuki K, Takahashi H, Sano H, et al. Impaired regulatory $\mathrm{T}$ cell reconstitution in patients with acute graft-versus-host disease and cytomegalovirus infection after allogeneic bone marrow transplantation. Int J Hematol (2012) 95(1):86-94. doi: 10.1007/s12185-011-0976-7

23. Pastore D, Delia M, Mestice A, Perrone T, Carluccio P, Gaudio F, et al. Recovery of CMV-specific CD8+ T cells and Tregs after allogeneic peripheral blood stem cell transplantation. Biol Blood Marrow Transplant (2011) 17 (4):550-7. doi: 10.1016/j.bbmt.2010.04.011

24. Wingate PJ, McAulay KA, Anthony IC, Crawford DH. Regulatory T cell activity in primary and persistent Epstein-Barr virus infection. J Med Virol (2009) 81(5):870-7. doi: 10.1002/jmv.21445

Conflict of Interest: The authors declare that the research was conducted in the absence of any commercial or financial relationships that could be construed as a potential conflict of interest.

Copyright $(2021$ Zhou, Shi, Wei, Wang, Yan, Zhang, Xu, Liu, Huang and Sun. This is an open-access article distributed under the terms of the Creative Commons Attribution License (CC BY). The use, distribution or reproduction in other forums is permitted, provided the original author(s) and the copyright owner(s) are credited and that the original publication in this journal is cited, in accordance with accepted academic practice. No use, distribution or reproduction is permitted which does not comply with these terms. 